\title{
El devenir inhumano en El desván, de Ramón H. Jurado ${ }^{1}$
}

\section{(The Becoming-Inhuman in El desván, by Ramón H. Jurado)}

\section{Fernando Burgos Pérez ${ }^{2}$}

University of Memphis, Estados Unidos

\begin{abstract}
Resumen
En este análisis de la novela El desván, de Ramón Jurado, se discute el concepto de devenir inhumano en cuanto crítica del positivismo. Apuntando a sus diferencias, se explica que la obra de Francisco Clarck, A través del tormento es el referente de El desván. Se comenta el efecto en la novela de Jurado de referentes como La náusea de Sartre, El pozo de Onetti, y El extranjero de Camus, novelas que constituyeron un trasfondo significativo para la plasmación existencialista de la obra de Jurado. Finalmente, se estudia el invasivo elemento de lo libidinal en la novela.
\end{abstract}

\begin{abstract}
In this analysis of the novel El desván [The Attic], by Ramón Jurado, the concept of becoming-inhuman as a criticism of positivism is discussed. Concerning its differences, an explanation is provided of how $A$ través del tormento, by Francisco Clarck, is the referent of El desván. Attention is given to the impact on Jurado's novel of works whose existentialist dimension offers a significant background for the writing of El desván. These include Nausea by Sartre, El pozo by Onetti, and The Outsider by Camus. Finally, the pervasive element of the libidinal in Jurado's novel is addressed.
\end{abstract}

1 Recibido: 4 de junio de 2018: 17 de setiembre de 2018.

2 University of Memphis, Tennessee, Estados Unidos. Correo electrónico: fburgos@memphis.edu

LETRAS 64 (2018), ISSN 1409-424X; EISSN 2215-4094 
Palabras clave: literatura panameña, Ramón Jurado, Francisco Clarck, el devenir inhumano, sexualidad y muerte.

Keywords: Panamanian literature, Ramón Jurado, Francisco Clarck, the becoming-inhuman, sexuality and death.

\section{Perspectivas sobre el concepto de devenir inhumano}

Postrado en una cama durante casi dos decenios, confinado en el exiguo espacio de un altillo, y - con excepción de la insólita relación con una mujer - incomunicado del resto del mundo, el protagonista de la novela de Ramón Jurado confronta en esta extrema forma de apartamiento el descenso en una zona de exclusión reconocible con un devenir inhumano. Utilizo el concepto filosófico devenir desarrollado por Deleuze y Guattari, por lo cual éste «no es una correspondencia entre relaciones, ni una semejanza, ni una imitación, ni una identificación» ${ }^{3}$. Así, nadie produce una lista de lo que es humano para saber en qué reside lo inhumano, aunque tampoco el conocimiento de lo que es humano nos dirige a una comprensión de lo inhumano. Este último es un territorio del que no se quiere hablar, tan solo un término invocado - la mayoría de las veces - como exclamación de conmiseración frente a lo que se percibe como una condición inaceptable de existencia. Y, sin embargo, para citar tan solo un ejemplo, las diversas aplicaciones económicas del neoliberalismo —a través la creación de mega-corporaciones internacionales - han llevado a abusivas condiciones sociales, las cuales indudablemente son inhumanas, aunque por lo general, y a pesar de contar con denuncias, tales situaciones desembocan en completa indiferencia.

Bloquear la visión de lo inhumano es un acto tan natural como eludir la vista frente a una escena grotesca. Suprimir el escenario de lo inhumano se correlaciona con la defensa psicológica de confort en la zona de lo que socialmente se entiende por humano, es decir,

3 Gilles Deleuze y Félix Guattari. A Thousand Plateaus. Capitalism and Schizophrenia (Minneapolis: University of Minnesota Press, 2007) 237. Traducción del autor del artículo. 
en un espacio defensivo de lo que no incomoda, de suerte que ni siquiera la real ocurrencia de lo inhumano llegue a ser percibida como insensibilidad o apatía. Junto a lo que el ángulo más patente y visual de lo sociológico nos lega sobre la significación de lo inhumano y cuya óptica reside fundamentalmente en una perturbadora imagen de sufrimiento, se encuentra la enorme portabilidad significante de ello en su aproximación artística y filosófica. Lyotard recuerda esta diversidad de registros citando al poeta francés Apollinaire quien afirmara: «Más que cualquier otra cosa, los artistas son seres que quieren devenir inhumanos $»^{4}$ y la del filósofo alemán Theodor Adorno cuando éste señalara que «la lealtad del arte hacia el género humano reside en su inhumanidad $\iota^{5}$. En ambos casos se buscan un principio de diferencia a través del cual se pierda el centrismo de lo humano a fin de permitir una eliminación de los estereotipos humanistas y la inclusión, por tanto, de otros devenires. Lo inhumano en este caso hace multivalente la base de referencia hacia lo humano.

En Les peintres cubistes, Méditations esthétiques ${ }^{6}$, Apollinaire se refiere al surgimiento del cubismo en la obra de artistas como Picasso, Braque, Duchamp, Metzinger, y Picabia, entre otros pintores, sobre una vanguardia en la cual la representación figurativa de lo humano desaparecía puesto que ello constituía en realidad no sólo una limitación con respecto a una comprensión profunda de lo humano, sino que además eliminaba la multiplicidad de sus dimensiones. Así, el geometrismo y la tendencia a la fragmentación de la imagen en estas pinturas llevarían a la postre a una representación completamente abstracta en la cual lo humano desaparecía entendido como la proximidad de lo reconocible en un nivel real. Se trataba en el fondo del paso necesario de un arte que en realidad no tenía nada de inhumano en un sentido social sino que por el contrario ampliaba al máximo

4 Jean-François Lyotard, The Inhuman. Reflections on Time (Stanford, California: Stanford University Press, 1991) 2. Traducción del autor del artículo.

5 Lyotard, 2. Traducción del autor del artículo.

6 Guillaume Apollinaire, Les peintres cubistes, Méditations esthétiques (París: Eugène Figuière Éditeurs, 1913). 
todos los significantes de lo humano que habrían yacido ocultos en una plasmación clásica.

En el caso de la afirmación de Adorno, el contexto era el de oponerse a la idea kantiana del arte como sirviente social. Es decir que para Adorno en la medida que el arte fuese utilizado ideológicamente quedaba sujeto a alguna forma de fraude o falsificación de lo humano en aras de esa exposición ideológica. De allí que Adorno llegase a afirmar que «La humanidad del arte es incompatible con cualquier ideología que sea servicial al género humano» ${ }^{7}$. Lo que se empieza a advertir aquí en una conexión con la novela de Jurado es que en el devenir inhumano residiría lo más humano que la portabilidad artística puede entregar. Entendido en este sentido, la realización de devenir inhumano a través del arte acarrea una imponente crítica de las construcciones sociales. Adicionalmente, el retrato de lo inhumano va a generar una reflexión sobre el arte y el tiempo. Sobre el arte, puesto que - en el discurso crítico de lo inhumano- éste sería el único espacio donde la transparencia es posible y no requeriría de justificaciones de ningún tipo ni de complacencias hacia un sector social determinado. Sobre el tiempo, porque esta dimensión y la de lo inhumano se aproximan en su realización metafísica tanto desde el punto de vista del arte como de la filosofía. Como señala Lyotard, «no se puede escribir sin ser testigo del abismo del tiempo en su devenir $\rangle^{8}$.

En El desván, de 1954, la reclusión de su personaje Federico Calvo en un espacio mínimo de la casa, acrecienta un retrato de lo inhumano al intensificarse esa forma radical de aislamiento con la dolencia que afecta al protagonista, una tuberculosis de la cadera; condición que lo va debilitando hasta impedirle el movimiento: «Como siempre, fue en la mañana. Lo supe al despertar: no podía moverme. Mis piernas estaban tiesas, como entablilladas por varillas de acero» ${ }^{9}$.

7 Theodor W. Adorno, Gretel Adorno y otros, Aesthetic Theory (London, New York: Continuum, 2002) 197. Traducción del autor del artículo.

8 Lyotard, 74. Traducción del autor del artículo.

9 Ramón H. Jurado, El desván (Panamá: Editorial Manfer, 1995) 72; en adelante el número de página se indicará entre paréntesis. 
La novela está enmarcada por una carta que el propio autor Ramón Jurado ha hecho llegar a un doctor y en la cual lo insta a revelarle la verdad sobre quien va a ser el protagonista de la novela: «¿Pudo ser cierto aquel tormento? ¿Existió Federico Calvo? ¿Es mentira tanto dolor? Yo deseo, doctor, saber si usted se atreve a negar la existencia de Federico Calvo. Esta es mi petición. Y esa es su responsabilidad» (24). A su vez la novela es el legajo que ha escrito el personaje: «Tal como la recibí así os la envío. De inmediato numeré las hojas de que consta porque es sumamente importante que ninguna se extravíe» (24), recurso literario de la modernidad desde Cervantes adelante.

\section{Antecedente de la obra de Jurado y planos estéticos de su diferenciación}

Un aspecto en el análisis de esta novela de Jurado es la de su relación con el libro de Francisco Clarck (1886-1933) A través del tormento $^{10}$, cuya primera edición es de 1931, se reedita en 1960 y luego en el 2007 en una impecable edición realizada por la Universidad Tecnológica de Panamá. El relato-crónica narra las dos décadas de debilitamiento, padecimiento y postración de Clarck debido a una enfermedad de origen reumático (artritis), la cual en la edición de 2007 es diagnosticada por el doctor Antonio Cachafeiro como una espondilitis anquilosante ${ }^{11}$. El relato de Clarck no ahorra ninguno de los detalles debilitantes de su condición, incluyendo aspectos sórdidos: «Consideraba yo las cucarachas como inofensivas para el hombre; pero una noche, por fortuna estando despierto, las dentelladas desgarradoras e increíbles de una en la boca de la uretra me enseñaron lo contrario» ${ }^{12}$. Tampoco crea un estado de benevolencia para sí mismo, por el contrario, el retrato general llega a ser despiadado, así como la enfermedad lo es con él: «Soy un cadáver viviente. Quizá mi caso se

10 Francisco Clarck, A través del tormento (Panamá: Universidad Tecnológica de Panamá, 2007).

11 Clarck, 233-235.

12 Clarck, 28. 
admita en comparación con las torturas espantosas del Dante o con los suplicios de las leyendas mitológicas griegas $\rangle^{13}$.

El hecho de que la obra de Clarck viniese a formar un ente artístico constitutivo de El desván, nunca llegó a traducirse en un dilema estético para Jurado puesto que decidió hacer explícita la relación con la obra de Clarck internamente en su novela. En una suerte de prefacio de El desván, Jurado dedica esta obra a Francisco Clarck: «Quiere esta novela rendir homenaje al dolor y a la grandeza de Francisco Clark (sic). Su libro, olvidado y al margen de la memoria panameña, es un hermoso alegato sobre la mansedumbre ${ }^{14}$. Adicionalmente, el nombre de su personaje Federico Calvo representa a través de las letras iniciales del nombre y apellido, las de Francisco Clarck. Su intención era preservar la memoria de la extraordinaria realización del texto de Clarck y al mismo tiempo destacar que $A$ través del tormento debía leerse no sólo como la biografía de un caso médico, sino que también como un logro artístico de extraordinaria categoría en las letras panameñas. Y la mejor manera de hacerlo para Jurado no era con la redacción de un ensayo sino a través de la literatura de suerte que se pudiese apreciar los varios niveles estéticos del libro de Clarck.

Estos aspectos han llevado a señalar el libro A través del tormento como la base inspiración de El desván. Los estragos de la enfermedad, la reclusión del personaje, su inmovilidad como un enfoque obsesivo enlazarían ambas obras. Sin embargo, la intensa dimensión metafórica de la novela de Jurado, su base filosófica existencial y la gravitación de lo sexual son claras fuerzas estéticas que separan completamente ambas obras. Jurado sabía perfectamente que una obra que toma como antecedente a otra no podía entenderse solo a nivel de inspiración, término este último desprestigiado, además, en el contexto de los desenlaces que había experimentado la literatura hispanoamericana de la modernidad desde Darío adelante. Esta aclaración no le resta mérito

13 Clarck, 25.

14 Jurado, 17. Mantengo la ortografía del apellido en la obra de Jurado como Clark en lugar de Clarck. 
a la obra de Clarck, la cual cuenta con un rico e innovador caudal artístico. En lo que respecta al distanciamiento entre la novela que se crea y su antecedente, Jurado estaba consciente de la modernidad estética de su obra y quiso asumirla cabalmente. Se puede citar muchos ejemplos al respecto en el caso de la literatura a nivel mundial. El más conocido, por supuesto, es el de Cervantes quien trabajó finamente la dialéctica de incluir y satirizar la novela de caballería, pastoril, y picaresca, creando con Don Quijote la primera novela moderna en Occidente.

Jurado retoma esta tradición moderna, la cual en su caso se correlacionaba, además, a la proyección vanguardista de su novela. De este modo, asume completamente el diálogo de inclusión y separación de su antecedente. La razón es que el escritor panameño quería que su novela fuese más allá de un tratamiento empírico sobre la dolencia del ser humano, logrando arribar a planos metafísicos sobre la existencia y la muerte. Los puntos que se analizaron a continuación en este apartado dedicado a esclarecer la dialéctica de la obra de Jurado con la de Clarck están destinados a precisar las vías modernas del entorno de El desván, las cuales conferirían las bases de la extraordinaria renovación literaria de la novela de Jurado.

Una de las constantes estéticas de las expresiones de la modernidad desde las vanguardias de los años veinte y treinta del siglo pasado fue constituida por una representación artística que hacía la crítica de las devastadoras consecuencias de la confianza absoluta que se generara en el desarrollo de la ciencia y la tecnología y al hacerlo en lugar de colocar como figura central al ser humano, éste o bien desaparecía en función de una concepción abstracta de la imagen, o bien se le retrataba con signos y perfiles que se alejaban de lo que normalmente se asociaba a lo humano.

Esta tendencia en el lapso del siglo xx alcanza su punto más radical en la obra del artista polaco Zdzislaw Beksinski quien mediante su pintura distópica recrea escenarios aterradores de desolación y muerte que precisamente se coloca en las antípodas de la estruendo 
celebratorio de las tecnologías de informática de las últimas cuatro décadas que cambiarían radicalmente el medio y modo de las comunicaciones en el mundo así como también del avance de las ciencias con respecto a la especulación sobre la existencia de infinitos universos (multiverso en lugar de universo) y los nuevos tratamientos en el área de salud relacionados a la genética médica. Ciertamente, la novela de Jurado se nutrió de estas representaciones, impulsando la narratividad de El desván a un profuso despliegue simbólico que desembocaría en planos abstractos de gran productividad, provocativos e innovadores en la narrativa hispanoamericana.

La captación de lo que este arte se proponía, al alejarse de una representación que cuadrara con una óptica realista y en la cual, además, la figura humana fuera central a la expresión artística, dio origen paralelamente a manifiestos que discutían las profundas transformaciones y nuevos roles del arte y que en el fondo venían a ser parte de la dialéctica vanguardista en la que la creación y la crítica se hacían inseparables. En la ribera filosófica, el pensador español Ortega y Gasset publicaba en 1925 La deshumanización del arte, en que describía así este distanciamiento de lo humano:

Lejos de ir el pintor más o menos torpemente hacia la realidad, se ve que ha ido contra ella. Se ha propuesto denodadamente deformarla, romper su aspecto humano, deshumanizarla. Con las cosas representadas en el cuadro tradicional podríamos ilusoriamente convivir... Con las cosas representadas en el cuadro nuevo es imposible la convivencia: al extirparles su aspecto de realidad vivida, el pintor ha cortado el puente y quemado las naves que podían transportarnos a nuestro mundo habitual. Nos deja encerrados en un universo abstruso, nos fuerza a tratar con objetos con los que no cabe tratar humanamente ${ }^{15}$.

15 José Ortega y Gasset, La deshumanización del arte y otros ensayos de estética (Madrid: Espasa Calpe, 2005) 60. 
En el mismo ensayo Ortega y Gasset hizo una afirmación con respecto al dinamismo y fluidez del pensamiento que se colocaría entre una de las aserciones más cautivantes del espíritu moderno: «Nuestras convicciones más arraigadas, más indubitables, son las más sospechosas. Ellas constituyen nuestro límite, nuestros confines, nuestra prisión» ${ }^{16}$. Esta apertura, sin embargo, no se reflejaba completamente en esta obra de 1925, en la cual su visión sobre el arte de vanguardia se estrechaba en sus conclusiones: «Se dirá que el arte nuevo no ha producido hasta ahora nada que merezca la pena, y yo ando muy cerca de pensar lo mismo» ${ }^{17}$. Algunos de los postulados de esta obra han ido perdiendo vigencia y la razón de referirme a ella tiene que ver con aquellas afirmaciones en las cuales la percepción de la ausencia de humanidad en el arte parece ser una crítica de lo que el nuevo arte de esa esa época perdía en relación a su tradición. Veamos, por ejemplo, la siguiente declaración del pensador español: «Pues bien: yo diría que el arte situado antes - como la ciencia o la política - muy cerca del eje entusiasta, sostén de nuestra persona, se ha desplazado hacia la periferia» ${ }^{18}$.

Esa supuesta negatividad de una migración artística hacia la periferia, es decir de una descentralización del enfoque en lo que comúnmente se asociaba a lo humano, iba a constituirse en un manantial de enriquecimiento artístico y filosófico sobre la compleja dialéctica del ser humano y de su problemática relación con el entorno social. Esta detención en la periferia — que era el sustantivo modus operandi de la ideología artística de El desván - acogía una multiplicidad de expresiones estéticas y cuyo amplio rango podía registrar desde una completa abstracción hasta la representación de lo inhumano. La perturbación que causaba esta última provenía del hecho que para ser auténtica y netamente existencial no podía dejar de ser abstracta, conceptual y simbólica.

16 Ortega y Gasset, 62.

17 Ortega y Gasset, 85.

18 Ortega y Gasset, 83. 
La crítica en El desván hacia lo que se entiende como ciencia o progreso apunta a la medicina y se da en el contexto de la enfermedad de su protagonista cuya posibilidad de tratamiento a través de la cirugía es continuamente postergada mientras Federico Calvo se encuentra en el vestíbulo de la sala de operaciones. La demora de su tratamiento es retratada con planos del absurdo artístico en la caracterización de doctores que están siempre ocupados, y recalcada en el prefacio - el cual se integra en realidad a la novela - que el autor Ramón Jurado dirige a un doctor, haciendo hincapié en la soberbia de un conocimiento insustancial y la envanecida postura que trae consigo la arrogancia de ocupar un sitial de poder en el saber: «Es el caso, que su última charla dejó en mí una profunda desilusión. Desagrado, más bien. Me pareció usted ridículo, absurdo. Si supiese lo petulante que lucía cuando hablaba alegremente sobre el tiempo y la muerte» (19).

Como refutación a tal actitud cientificista de la institucionalidad médica sobre conceptos existenciales como la muerte y el tiempo tratados de modo empírico, El desván los plasmará en su estatuto filosófico conectando el tiempo a una dimensión introspectiva en la cual la temporalidad, es decir, lo que ordinariamente se discierne como transcurso no existe. La muerte por otro lado se ve como inexistente en su devenir físico y reemplazada más bien por la experiencia de atravesar «un pozo inacabable con la boca amarrada» (62). Es decir, la muerte adviene la conciencia de vivir, de haber sido arrojado en la existencia, premisa esencial del existencialismo en la línea de Heidegger. Esto explica el hecho narrativo de que cada vez que se menciona la presencia de ratones en el desván donde se encuentra el protagonista, en lugar de detenerse en el potencial naturalista de su grotesco, estos animales se correlacionan con una detracción hacia el ser humano y las instituciones médicas como puede apreciarse en la siguiente cita: «Aquí, arriba, en este oscuro desván de trastos viejos, descubrí por primera vez la perversidad de los hombres, de los ratones» (27) y «Yo tenía miedo, miedo. Sé que temblaba, que me estremecía todo. No por el dolor, que ya en esos momentos no lo sentía. Tampoco era 
la muerte porque no existe. Existen sí, los ratones, los médicos, las salas de operaciones» (62). Además, se alude constantemente a un ratón que sería el sabio y a sus propósitos de dejarlo sin luz:

Enemigos de esta lámpara que nunca reposa, murmuraron toda la noche en una tertulia hambrienta y de rato en rato, el mayor, el sabio, asomaba sus ojos enormes, sus dientes de clavo y sonreía ... Desde hace día conozco sus propósitos: destruir la única lámpara que alumbra mi vida (27-28).

En este punto es evidente el extensivo empleo de la metáfora en la novela, los usos figurados de ratón sabio y medicina y la construcción alegórica del desván como el reconocimiento final de que la condición del ser humano - aun teniendo en cuenta su relacionamiento social - es la metafísica de su propia soledad.

Se puede estar de acuerdo con la idea bachelardiana de que, si se quisiera realizar «un estudio fenomenológico de los valores de intimidad del espacio interior, la casa es, sin duda alguna, un ser privilegiado» ${ }^{19}$, pero en su aserción de que «la casa es un cuerpo de imágenes que dan al hombre razones o ilusiones de estabilidad $»^{20}$, e intentando llevar esto a $E l$ desván habría que puntualizar que no hay esperanza sobre un alcance de estabilidad en la novela de Jurado. Lo mismo en cuanto a ese encuentro útil que Bachelard observa entre la fenomenología y el psicoanálisis para detectar ciertos parámetros de universalidad de la imagen en los espacios. Señala Bachelard que en la verticalidad de la casa se juega una dialéctica entre lo bajo y lo alto, representada por los espacios del sótano como el del inconsciente y lo consciente para el desván. Siguiendo en este respecto a Jung indica que en la buhardilla hay

ratas y ratones [que] pueden alborotar a gusto. [Pero] Si aparece el señor, volverán silenciosos a su escondite. En el sótano se mueven

19 Gaston Bachelard, La poética del espacio (México: Fondo de Cultura Económica, 2000) 27.

20 Bachelard, 37. 
seres más lentos, menos vivos, más misteriosos. En el desván los miedos se racionalizan fácilmente. En el sótano, incluso para un ser más valiente que el hombre evocado por Jung, la racionalización es menos rápida y menos clara; no es nunca definitiva. En el desván la experiencia del día puede siempre borrar los miedos de la noche ${ }^{21}$.

La limitación del análisis fenomenológico y psicoanalítico reside en la creencia de una realización determinada del imaginario cuyas vertientes muestran cierta regularidad. El problema de esa aproximación es no sólo descontar la ocurrencia patafísica — es decir como lo vio Alfred Jarry: un universo de excepciones - sino que también el quiebre total que la actividad imaginante es capaz de desencadenar con respecto al imaginario que se ha ido configurando en torno al arte.

No hay racionalización de los temores en la novela de Jurado. Por el contrario, estos van escalando hasta hacerse atormentadores. Primero, presenciamos la perplejidad de su situación: «No sé por qué una sensación de inseguridad se apoderó de mí. Debe ser la soledad o quizá el temor de que Zoraida se enfermara repentinamente» (75). Segundo, esas dudas sobre sí mismo convertidas en un desconcierto alucinante: «¿Hasta dónde esta muchacha increíble no es también obra maléfica de la anquilosis? ¿Puede ser realidad, la única realidad en este desván lleno de polvo y dolores?» (79). Y finalmente, la manera como la estupefacción de esas aprensiones que llegan al pánico corona en la duda definitiva que sería la negación de sí mismo: «Estoy aterrorizado porque no sé si vivo. No es eso: si una vez viví» (84).

En la consciente selección en la novela de Jurado de un espacio de la casa como el de la buhardilla en el cual no transcurren las actividades de socialización del ser humano sino, por el contrario, las de su propio aislamiento, en la constante crítica del positivismo, así como de las actitudes arrogantes de las ciencias y en particular de la medicina, en la configuración de cuadros narrativos abstractos que reemplazan una secuencia progresiva de eventos, en la representación

21 Bachelard, 39. 
de un protagonista cuya dolencia física se va transformando en una agonía existencial y finalmente, en el levantamiento de una metafísica que conduce la visión de mundo de la novela, El desván deja de apuntar a los antecedentes de su surgimiento en una obra previa para proyectarse con su propia y original conductividad artística.

\section{Contexto de la literatura existencialista}

La historia de El desván converge como un diario del hundimiento del yo, en una gradual disipación de su concreción física, lo que acarrea como consecuencia el desplazamiento del ser como centro cognoscitivo. Sin embargo, contrariamente a una caída en la nada total o en la muerte, este estado de inhumanidad crea una conciencia existencial: «Esta posibilidad terrible de no existir es lo que mantiene mis ojos en eterna vigilia» (79). Esta angustia existencial aparte de su soporte filosófico — Søren Kierkegaard, Martin Heidegger, Friedrich Nietzsche, Jean Paul Sartre- encontraba en las décadas que escribía Jurado todo un contexto literario cuyas figuras centrales en Europa serían Jean Paul Sartre con La náusea en 1938 y Albert Camus con El extranjero en 1942; y en Latinoamérica, Juan Carlos Onetti con la publicación de El pozo en 1939.

El protagonista de La náusea, Antoine Roquentin, deambula por la ficticia ciudad de Bouville dedicado a una investigación sobre el Marqués de Rollebon, un noble del siglo dieciocho. Tal como el mismo Antoine lo insinúa en el diario de vida que mantiene es un ser poseído por la náusea de vivir, lo cual en su entorno significa el día a día de una existencia en la que cualquier actividad que se acometa como significativa termina por demostrar su lado absurdo, de modo que lo que se va a instalar finalmente en el ser humano que tenga esta conciencia es un vacío de la existencia. Las siguientes palabras del protagonista muestran esa sensación de que nada vale la pena: 
Cuando uno vive, no sucede nada. Los decorados cambian, la gente entra y sale, ¿o es todo? Nunca hay comienzos. Los días se añaden a los días sin ton ni son, en una suma interminable y monótona. De vez en cuando, se saca un resultado parcial; uno dice: hace tres años que viajo, tres años que estoy en Bouville. Tampoco hay fin: nunca nos abandonamos de una vez a una mujer, a un amigo, a una ciudad. Y además, todo se parece: Shangai, Moscú, Argel, al cabo de quince días son iguales. Por momentos — rara vez - se hace el balance, uno advierte que está pegado a una mujer, que se ha metido en una historia sucia. Dura lo que un relámpago. Después de esto, empieza de nuevo el desfile, prosigue la suma de horas y días. Lunes, martes, miércoles. Abril, mayo, junio. 1924, 1925, $1926^{22}$.

En el caso de El extranjero de Camus, su protagonista Meursault fue condenado a muerte por un asesinato. En el proceso de su acusación se desenvuelve el perfil de una persona que descree de todo y que se siente un extraño o extranjero en su propio entorno social. Lo envuelve una total indiferencia a cualquier rito social sea la muerte de su madre o la perspectiva de matrimonio:

María vino a buscarme por la tarde y me preguntó si quería casarme con ella. Dije que me era indiferente y que podríamos hacerlo si lo quería. Entonces quiso saber si la amaba. Contesté como ya lo había hecho otra vez: que no significaba nada, pero que sin duda no la amaba. ¿Por qué, entonces, casarte conmigo?, dijo. Le expliqué que no tenía ninguna importancia y que si lo deseaba podíamos casarnos. Por otra parte era ella quien lo pedía y yo me contentaba con decir que sí. Observó entonces que el matrimonio era una cosa grave. Respondí: No. Calló un momento y me miró en silencio. Luego volvió a hablar. Quería saber simplemente si habría aceptado la misma proposición hecha por otra mujer a la que estuviera ligado de la misma manera. Dije: Naturalmente ${ }^{23}$.

22 Jean Paul Sartre, La náusea (México: Época, 1976) 32-33.

23 Albert Camus, El extranjero, trad. Bonifacio del Carril (Madrid: Alianza, 1971) 52. 
Su condena él la ve como la punición que todos tienen en el sentido existencial de que el ser humano nace arrojado a la muerte. Y esta es la única certeza de cualquier futuro. En El pozo de Onetti, las memorias de un escéptico personaje como Eladio Linacero lo llevan a un concepto de vida en el que debe darse las espaldas a la realidad y preferir un mundo de evocaciones, invenciones, ficciones, y sueños que le devuelven el tono sombrío de su existencia y el encuentro con la indiferencia del tiempo:

Hace un par de años que creí haber encontrado la felicidad. Pensaba haber llegado a un escepticismo casi absoluto y estaba seguro de que me bastaría comer todos los días, no andar desnudo, fumar y leer algún libro de vez en cuando para ser feliz. Esto y lo que pudiera soñar despierto, abriendo los ojos a la noche retinta. Hasta me asombraba haber demorado tanto tiempo para descubrirlo. Pero ahora siento que mi vida no es más que el paso de fracciones de tiempo, una y otra, como el ruido de un reloj, el agua que corre, moneda que se cuenta. Estoy tirado y el tiempo pasa. Estoy frente a la cara peluda de Lázaro, sobre el patio de ladrillos, las gordas mujeres que lavan la pileta, los malevos que fuman con el pucho en los labios. Yo estoy tirado y el tiempo se arrastra, indiferente, a mi derecha y a mi izquierda ${ }^{24}$.

Estas tres novelas que anteceden a El desván sitúan el contexto de escritores hondamente afectados por el desenvolvimiento de una Historia que testimoniaba la violencia de dos guerras mundiales y en particular el surgimiento del nazismo y las atrocidades del exterminio humano. Las novelas de Sartre y Camus adoptan una técnica sin grandes quiebres narrativos. A diferencia de la novela de Onetti que sí cuenta con formas narrativas rupturales y más en consonancia con inmersiones introspectivas y de un fluir de conciencia que escapa a la tutela de un narrador en control.

24 Juan Carlos Onetti, El pozo, Obras completas (México: Aguilar, 1970) 49-76 (76). 
En El desván confluyen los aspectos filosóficos del existencialismo de estas tres novelas, y una de las más significativas es que en la novela de Jurado no es sólo el personaje el que deambula por la nada sino que lo es también su visión sobre la totalidad del entorno social, criticando las actividades del ser humano como una rutina sin sentido: "A menudo me alegra saber que la humanidad tampoco vive... Sé que todo el mundo duerme ocho, diez horas diarias. Otros más. Luego salen a la carrera para sus trabajos: ocho horas también... Es curioso la gente tiene miedo de pensar y está viva, viva como yo» (63). Sin embargo, en lo que respecta a la técnica, está más próxima a la del escritor uruguayo que a lo de los franceses. También, la une a la de Onetti un volcamiento de lo sexual que es muy significativo en obras en las que la derrota existencial es una certeza. El objetivo de haberme referido a estas tres novelas de fines de la década del treinta del siglo pasado consiste en llamar la atención sobre el tipo de literatura que había surgido unos dieciséis años antes que Jurado publicara El desván y que la literatura existencialista, así como otros grandes movimientos artísticos, contaba con un despliegue a nivel internacional. Evidentemente, un análisis exhaustivo de las tres obras, así como una propuesta comparativa de estas novelas con la de Jurado no forma parte del alcance de este ensayo. Lo que ha conducido la redacción de este apartado es la identificación de las bases estéticas y las corrientes artísticas a las que el escritor panameño había tenido acceso en su formación intelectual y como ello llegaría a constituir un contexto extraordinariamente relevante para Jurado.

$\mathrm{Al}$ respecto se puede apreciar que ya desde los títulos de las novelas de Sartre, Camus y Onetti se anticipan los símbolos de distanciamiento social y de desconfianza hacia los llamados progresos de la modernización de la primera mitad del siglo veinte. Estos escritores reaccionaban con un sentido de repulsión y desapego hacia esta idea sobre todo en el contex to histórico de destrucción y muerte que traerían el surgimiento del nazismo y la segunda guerra mundial. El título de la obra de Jurado se relaciona a ese contexto literario internacional 
de una narrativa de fuertes tonos existencialistas primero porque el espacio de la novela se constriñe a un lugar de la casa que no es el social y en segundo lugar la caracterización de un caso de dolencia extrema del personaje converge gradualmente como un símbolo de su refugio en la soledad. Esta idea de separación convoca el espíritu existencialista de demostrar los niveles extremos de absurdo a los cuales puede llegar el ser humanon el caso de la literatura hispanoamericana, aparte de El pozo y antes de la aparición de El desván, Onetti había publicado en 1950 La vida breve, construyendo una diversidad de planos de lo ficticio y deconstruyendo, por otro lado, el amparo del ser humano en lo trascendental. Asimismo, en 1943 y en 1948, Eduardo Mallea y Ernesto Sábato habían publicado respectivamente Todo verdor perecerá y El túnel, obras de sorprendentes encuentros entre lo psicológico y lo existencialista. Adicionalmente, durante pleno periodo del vanguardismo latinoamericano, el escritor ecuatoriano Pablo Palacio había realizado una gran contribución avant la lettre a la narrativa existencialista con sus dos novelas Débora (1927), Vida del ahorcado (1932) y la colección de cuentos Un hombre muerto a puntapiés (1927), obras que junto a su dimensión existencial añadían complejos planos metanarrativos. En suma, cuando Ramón Jurado comenzó a escribir El desván contaba con una sólida tradición literaria existencialista tanto en Europa como en Hispanoamérica. De esa tradición, el panameño había aprendido una importante lección que residía en el hecho de que la visión artística de lo existencial debía abrirse a múltiples vías de plasmación. Y es en esta realización que El desván alcanza una inmersión única en la modernidad artística, especialmente en los contextos de la literatura panameña y de Centroamérica. Los planos modernos de la constitución estética de su novela convergerían en una original multidimensionalidad en la que lo existencial se entrecruzaba con una crítica al positivismo, con los elementos de una sexualidad lasciva, y morbosa en ciertas instancias, y con una modalidad narrativa que privilegiaba la abstracción por 
sobre el desarrollo hilvanado o racional de eventos. Su obra narra deconstructivamente la dificultad de «estar» en el mundo.

\section{Lo metafísico y lo lúbrico en la novela de Jurado}

El desván es una obra completamente original en la plasmación de ese vacío de la existencia tanto temática como técnicamente. Y uno de los elementos que la hace más peculiar tiene que ver precisamente con la sexualidad que invade la totalidad de sus planos narrativos.

El protagonista de El desván es un ser en el que se siente y se respira cada uno de sus breves movimientos o ausencia de ellos como un paso hacia la muerte cuya semblanza es la eternidad de la nada. Fuera de la casa, es la bóveda del universo lo que lo aplasta. Dentro de la casa, es el arco del desván. En esa visión, el futuro es un sinfín de miedos y de sucesivas congojas. La mejor imagen en la novela de cómo ello se presenta para Federico Calvo es la de verse a sí mismo «detenido en el umbral de un gran portón» (78) conducido por «el desvarío, [y] la angustia» (79) y donde se le presenta «un inmenso presente sin movimiento y sin lamentos. La puerta abierta y yo de pie» (79). Y, sin embargo, esta visión del protagonista no habría sido posible sin Zoraida la mujer que lo atiende y quien permite la realización de la escritura pues es ella quien sostiene el papel sobre una tabla en la cual Federico Calvo logra apenas escribir con su mano izquierda estas cartas que son al mismo tiempo un diario y una novela. Zoraida habilita asimismo la única contextualización histórica de la novela cuando con su precaria habilidad de leer, silabeando con dificultad lee en un periódico lo siguiente: «I...tler..ha...bló en Mun...nnnn... ic...» (38).

Zoraida le clarifica a Federico Calvo que no ella no sabe escribir porque nadie se lo ha enseñado y al mismo tiempo se quiere dar énfasis en la novela que sin ella las cartas no habrían sido escritas y por ende tampoco la novela. Y a diferencia de las otras novelas que he comentado, la protagonista mujer aquí no aparece en referencias de 
ensoñaciones o en rememoraciones de deseo. Es más bien lo opuesto, ella convierte a Federico Calvo en su objeto del deseo hasta revelarse que su preocupación por él se transforma en completo dominio del protagonista masculino: «Estuve dos días sin moverme de la cama. Y Zoraida fue por primera vez feliz» (64).

Zoraida es más que un componente erótico de la novela; es una fuerza libidinal que surge repetidas veces a lo largo de la narración y que se hace invasiva. Sus prendas íntimas aparecerán en la cama de Federico Calvo, uno de sus senos se fugará para tocarle la mejilla o el pecho del protagonista, o ambos estarán continuamente flotando en la visión del escritor, agitándose sensualmente en frente de él. Voluptuosamente, el cuerpo de Zoraida dejará entrever sus nalgas, piernas y muslos, o se tenderá sin ropa en la cama, o caminará desnuda en el cuarto de Calvo aparentando buscar algo. Dice Freud que el adulto «preferiría confesar sus culpas a comunicar sus fantasías ${ }^{25}$, pero ya desde Sade con Justine en 1791 y La filosofía en el tocador en 1795 se sabe que el universo de la ficción cuenta con una dinámica en la cual la fantasía sexual y el discurso filosófico dialogan como en el caso de la obra del propio Sade, o la representación de un mundo absurdo en el cual se encuentra un hombre casi paralizado quien tampoco escapa de la dimensión sexual como lo demuestra la novela de Jurado. Retomando a Freud cuando indica que «Los instintos insatisfechos son las fuerzas impulsoras de las fantasías y cada fantasía es una satisfacción de deseos, una rectificación de la realidad insatisfactoria $»^{26}$, se podría especular que los parámetros de un entorno insoportable llevan a ese desenfreno sexual fantasioso de El desván, en cuyo caso sería irrelevante determinar - especialmente en el contexto de la subjetividad de cartas convertidas en diario personal- si esas escenas sexuales provienen del propio Calvo como escritor o de la observación real que él hace de Zoraida.

25 Sigmund Freud, «El poeta y los sueños diurnos», Biblioteca Virtual Universal en línea, 9 de abril de 2018, <http://www.biblioteca.org.ar/libros/211753pdf, s. p.>.

26 Freud, s. p. 
Lo palpable es la progresión lúbrica de lo concupiscente que incluye el hecho de que Zoraida se rasgue sus prendas interiores y llegue a jugar con el sexo de Federico Calvo en una escena lasciva en que a Zoraida: «los ojos se le incendiaban. Luego caía de rodillas junto a la cama buscándose algo entre las piernas. La vi terrible, peligrosa, rasgarse el traje entre los muslos» (82).

Al mismo tiempo, el desenfreno sexual, la excesiva apetencia de satisfacer deseos contenidos, el descontrol de la gratificación buscada, la obscenidad gráfica no dejan de mezclarse con los aspectos grotescos en torno a las mutilaciones que ha traído la enfermedad de Calvo. Justo cuando la expectativa de lo lúbrico se coloca en el alcance de su punto culminante, en medio de la intimidad sensual y de lo carnal, se desciende gélidamente hacia la morbidez producida por el cáncer de Calvo. Zoraida «metió la boca en el hueco que me dejaron en la pierna. Oí como si alguien rumiara» (82). La perturbadora reunión entre lo lúbrico y lo morboso no está muy distante del plano mayor metafísico de la novela en el cual al lector se la ha hecho leer una novela sobre un personaje cuya existencia es dudosa y es precisamente Zoraida, el significante de una energía libidinal máxima, quien ha respondido a la incertidumbre que obsesiona a Federico Calvo sobre si es cierto que él sea, a lo cual Zoraida responde sin conmiseración ninguna que no es verdad que él sea. Aparte de la cuestión filosófica existencial sobre si se es en la pura afirmación de la existencia o de si la existencia en sí, especialmente una mutilada de todo aquello que constituye al ser, no es suficiente, lo que nos queda en esta innovadora obra es la de haberse resaltado el privilegio de la ficción en el cual una de sus varias dimensiones reside en que Zoraida, Federico Calvo y los lectores han sido (hemos sido) engañados.

\section{Conclusiones}

La discusión del concepto de devenir inhumano conforme a una aproximación filosófica y estética tiene, en este ensayo, el objetivo de 
proveer un marco teórico relevante para una comprensión adecuada de la intencionalidad artística de la novela del escritor panameño. Por esta razón consideré que la opción de centrarse en los planos de anomalía médica del personaje presentaba el riesgo de producir una lectura plana de esta obra que impediría, además, una conexión con la conductividad metafísica de El desván. Siguiendo la idea de lo inhumano tanto en lo que señalan Deleuze y Guattari como Adorno mi análisis advierte sobre su funcionamiento multireferencial y su enlace con las propuestas existencialistas de la vanguardia. Cuando se investigan las expresiones artísticas de la vanguardia de 1920 a 1940, tanto las europeas como las latinoamericanas, se percibe que éstas buscaban evitar el foco en lo humano no porque se quisiese llegar a un anti-humanismo, sino que por el contrario se deseaba ingresar en la dimensión humana de una manera más profunda. De este modo fue que Apollinaire llegara a afirmar que había un deseo incluso en los propios artistas por devenir inhumanos. El surgimiento de un arte abstracto en el que la figura humana parece estar ausente, o la creación de un personaje cuyas condiciones extremas lleven a una caracterización inhumana son lineamientos estéticos significativos en la plasmación de un devenir inhumano en la novela de Jurado.

El segundo aspecto de mi trabajo argumenta que una hermenéutica de El desván no puede omitir su antecedente literario, la obra A través del tormento de Francisco Clarck, pero al mismo tiempo mantengo cuán crucial es distinguir la sustancial diferencia que separa ambas obras. Esto permite apreciar de qué manera la propuesta artística de la novela de Jurado involucra una crítica del espíritu positivista y de instituciones científicas como la medicina. Además, el escritor panameño incorpora una estética vanguardista en su novela, alejándose por completo de una narración lineal o de una que tuviera que presentar los eventos narrativos de un modo referencial, es decir explicando cómo el personaje llegó a una determinada situación. Por el contrario, en la textualidad de El desván se rehúye de aclaraciones que intenten dar una respuesta racional y por lo mismo se acude a 
una construcción narrativa muy abstracta cuyos símbolos deben ser decodificados en el plano de la lectura.

La tercera perspectiva de esta exégesis de la obra de Jurado consiste en establecer un enlace de El desván con la literatura de vanguardia de fines de los años treinta, en particular con aquella que se escribía a comienzos y durante los años de la segunda guerra mundial (1939-1945), lo cual conduce a la elucidación de un aspecto significativo del arte existencialista en el que el ser humano empezaba a cuestionar el sentido absurdo de la existencia. En este punto me pareció oportuno referirme a hitos narrativos importantes del panorama literario internacional de esos años, acudiendo así a dos ejemplos de la literatura europea La náusea y El extranjero y a uno de la literatura hispanoamericana, El pozo.

El último enfoque de mi ensayo revisa el entrecruce de lo existencial y lo libidinal en la novela. Un plano significativo en la visión de mundo de esta obra reside en la creación de un personaje que de acuerdo con el estatuto metafísico de la novela no vive el curso «normal» de una vida en el sentido de lo que sea una expectativa social, es decir, relaciones humanas afectivas, familiares ni tampoco de objetivos de realización personal a través de una profesión determinada, logros de éxito individual, persecución de principios religiosos o morales. En realidad, lo que la novela retrata es una especie de escena cinematográfica en la existencia de una persona. Subrayo el término existencia puesto que el personaje principal de El desván no tiene otra expectativa que la de sobrellevar la devastadora experiencia de su enfermedad. En su caso no hay el curso de una vida tal como se entiende socialmente sino apenas los rudimentos de una existencia mínima en la cual el ser se encuentra con el absurdo de «residir» en el mundo. Junto a esta dimensión, Jurado añade el elemento de lo lúbrico a través de la novela. Sin embargo, la invasiva plasmación de lo sexual en la obra tampoco redime al personaje de su condición absurda, sino que crea un plano hiperrealista de la existencia en la cual sexualidad y muerte se unen no para justificar el destino del ser humano sino su sinsentido. 
La inseparabilidad del plano lúbrico con la condición entrópica del ser humano es una contribución artística sumamente original que el escritor panameño llevó a cabo en el montaje de una novela metafísica de soporte vanguardista. 
